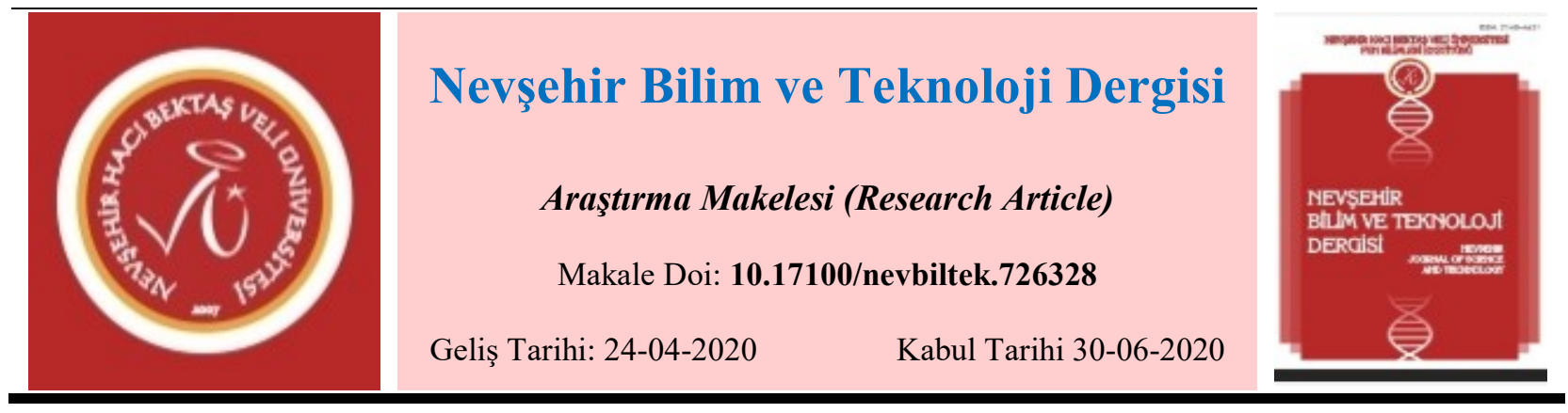

\title{
Kalsiyum Boratlı Antibakteriyel Sırların Hazırlanması ve Antibakteriyel Özelliklerinin İncelenmesi $^{1}$
}

\author{
Ebru ÇITAK ${ }^{1}$, , Bilal DEMIREL ${ }^{2}$,Gökçen YUVALI ÇELIK ${ }^{3}$, Fatih AKKURT ${ }^{4}$ \\ ${ }^{1}$ Erciyes Üniversitesi, Güzel Sanatlar Fakültesi, Seramik ve Cam Tasarımı Bölümü, Kayseri \\ ORCID ID: 0000-0002-5448-435X \\ ${ }^{2}$ Erciyes Üniversitesi, Mühendislik Fakültesi, Malzeme Bilimi ve Mühendisliği Bölümü, Kayseri \\ ORCID ID:0000-0002-5390-0630 \\ ${ }^{3}$ Erciyes Üniversitesi, Eczacılık Fakültesi, Farmasötik Biyoteknoloji Ana Bilim Dall, Kayseri \\ ORCID ID:0000-0002-3990-1346 \\ ${ }^{4}$ Gazi Üniversitesi, Mühendislik-Mimarlık Fakültesi, Kimya Mühendisliği Bölümü, Ankara
}

$\ddot{O ̈ z}$

Islak zemine sahip ortak kullanım alanları olan tuvaletler, lavabolar, klozet ve buralarda kullanılan diğer gereçler bakteri üremesi için çok uygun bir ortam oluşturmaktadır ve hastalıklara hatta bazen salgınlara yol açmaktadır. Bu çalışmada üretilecek olan antibakteriyel sırların bu gibi ortamlarda kullanılarak kullanıldığı yerlerde hastalık yapıcı mikroorganizmaların oluşmasına engel olması amaçlanmaktadır. Bu kapsamda, kalsiyum boratlı $\left(\mathrm{CaB}_{2} \mathrm{O}_{4}\right)$ antibakteriyel sırlar hazırlanmış ve antibakteriyel özellikleri incelenmiştir. Antibakteriyel etki için yüksek antibakteriyel aktiviteye sahip olan gümüş $(\mathrm{Ag})$ tercih edilmiş ve sır bileşeninin içerisine molce \%0,5 gümüş katılmıştır. Katkısız ve gümüş katkılı Kalsiyum Boratlı sır tozları soljel yöntemiyle üretilmiştir. Üretilen tozların XRD analizleri ile bu tozlardan üretilen sırların anti bakteriyel incelemeleri laboratuvar ortamında gerçekleştirilmiştir. Çalışma sonunda \%0,5 Ag katkılı kalsiyum borat sırlı seramik karoların E.coli üzerinde antibakteriyel etkiye sahip olduğu tespit edilmiştir.

Anahtar Kelimeler: Kalsiyum borat, Antibakteriyel sır, Antibakteriyel etki, E.coli.

\section{Preparation of Antibacterial Glazes with Calcium Borate and Investigation of It's Antibacterial Properties}

\begin{abstract}
Toilets, wash basins and commodes and the tools used in these places constitute a very suitable environment for bacteria reproduction because of their wet grounds. This paper aims to produce anti-bacterial glazes to be used in ceramic materials for the prevention of pathogenic microorganism emergence in these places. To this end, anti-bacterial glazes with calcium borate were prepared and their antibacterial properties were examined. Having a high antibacterial activity, Silver (Ag) was preferred for a high antibacterial effect, and 0,5\% mole silver was added into the glaze ingredient. Glaze powders with pure and silver added calcium borate was produced by sol-gel method. XRD analyses of the powders produced and the antibacterial properties of the glazes made of these powders were carried out in the laboratory. The analyses indicated that $0,5 \mathrm{Ag}$ added calcium borate glazed ceramic tiles had antibacterial properties in terms of emergence of E.Coli.
\end{abstract}

Keywords: Calcium borate, Antibacterial glaze, Antibacterial effect, E.coli.

1. Giriş

${ }^{1} \mathrm{Bu}$ çalışma Nevşehir Hacı Bektaş Veli Üniversitesi tarafindan 18-20 Ekim 2019 tarihinde düzenlenen International Conference on Materials Science and Technology Sempozyumunda sunulmuştur.

Sorumlu yazar e-mail: ecitak@erciyes.edu.tr 
Son zamanlarda, halk sağlığı sosyal bir ilgi konusudur. Hastaneler, kesimhaneler, restoranlar, endüstriyel tesisler vb. gibi kritik alanlarda patojenik mikroorganizmaların kirliliği ile ilgili haberler toplumda alarm ve endişe yaratmaktadır [1]. Özellikle seramik karolar; hastaneler, ticari binalar, kreşler, okullar, özel evler vb. gibi çeşitli uygulamalarda yaygın olarak kullanılmaktadır. Maalesef, bu tür seramik karolar antimikrobiyal aktiviteye sahip değildir ve mikroorganizmalar yüzeylerinde, özellikle sıcak ve nemli ortamlarda kolayca büyür, insan sağlı̆̆ına sorunlara neden olabilir. Bu nedenle, antimikrobiyal aktiviteye sahip karoların üretilmesi önemli bir yere sahiptir [2].

Bir antimikrobiyal yüzey fiziksel olarak, kimyasal olarak veya biyolojik olarak yayılan mikroorganizmaların çoğalmasını önleyen veya azaltan ajanlar içerir. Antimikrobiyal yüzeyler çoğunlukla fonksiyonel kaplamalardan oluşur [3]. Bazı ağır metallerin, özellikle de gümüş ve bakırın biyosit aktivitesi, 1940'larda antibiyotiklerin klinik olarak kullanılmasından önce bile birçok durumda yaygın olarak kullanılmıştır. Bu elementleri metalik iyonlar, bileşikler veya nano partiküller olarak içeren kaplamalar antibakteriyel koruyucu tabakalar olarak kullanılabilir [4].

Çay ekstraksiyonu, bakır, kitosan, çinko, titanyum dioksit, vb. gibi birçok doğal ve inorganik materyaller antimikrobiyal ajan olarak kullanılmıştır. Bununla birlikte, gümüş veya gümüş iyonlarının yaygın antibakteriyel aktiviteleri olduğu uzun zamandan beri bilinmektedir [5].

Antimikrobiyal özellikler sergileyen metal iyonları arasında, $\operatorname{Ag}(\mathrm{I})$ formundaki gümüş, geniş bir mikroorganizma spektrumuna bağlı olarak biyosidal etkisiyle iyi bilinmektedir. Bu sebeple geçmişte seramik sektöründe antimikrobiyal özelliklere sahip karoların esas olarak bu element kullanılarak kullanılması için çeşitli girişimlerde bulunulmuştur. Son araştırmalar nanometre büyüklüğünde gümüş parçacıklarının (1-100 nm) aynı zamanda antimikrobiyal özellikler gösterdiğini göstermiştir [1].

Ancak, antibakteriyel özelliğin etkinliği, metallerin homojenleşmesinde ve iyi dağılmasında yatmaktadır. Antibakteriyel seramik malzemeler ağırlıklı olarak gümüş birleşimlerle hazırlanır [6].

Seramik malzemelerde, antibakteriyel aktivite önemli bir konudur ve daha önce de bu konu ile ilgili çalışmalar yapılmıştır. Baheiraei, N. Ve diğerleri sol-jel yöntemiyle sırlı seramik karolarda $\mathrm{Ag} / \mathrm{SiO}_{2}$ ince filmin hazırlanması ve antibakteriyel aktivitesini incelemişlerdir. Kaplama filmleri, Gram-pozitif Staphylococcus aureus ve Gram-negatif Escherichia coli bakterilerine karşı mükemmel bir antibakteriyel performans sergilemiştir [5]. Seabra, M. P., ve diğerleri, antimikrobiyal etkili porselen karolar üretmişlerdir.Üretilen porselen karolar, S. aureus ve E. coli bakterileri için sırasıyla $\% 77$ ve \% 81'in üzerinde bir popülasyon azalmasını.göstermiştir [2]. Wang, Q., ve diğerleri mikro incelikte $\mathrm{Ag}_{2} \mathrm{WO}_{4}$ antibakteriyel tozların hazırlanması ve sıhhi seramiklerde uygulanması üzerine çalışma yapmışlardır. Mikro incelikte $\mathrm{Ag}_{2} \mathrm{WO}_{4}$ tozu $\% 90$ oranında antimikrobiyal etkiye sahiptir ve iyi bakterisit etki sergilemektedir [7]. Yoshida, H., ve diğerleri gümüş kil antimikrobiyal ajanlı porselen sırın antimikrobiyal etkisini incelemişlerdir. Kütlece \%0.008 Ag içeren sıra kütlece \%0,2 Zr eklenmesiyle yüksek bir antimikrobiyal aktiviteye sahip olmuştur [8]. Hasmaliza M., ve diğerleri seramik karo sırının içerisine mikron ve nano boyutta anataz katmışlar ve antibakteriyel performansını incelemişlerdir. Antibakteriyel özelliklerin kompozisyondaki anataz miktarı arttıkça arttığını gözlemlemişlerdir [9]. Niederhausern S. de., ve diğerleri endüstriyel seramik karoları yüzeylerinin temizlenebilirliğini ve antibakteriyel aktivitesini iyileştirmek için nano yapılı titanya-gümüş kaplama tasarlamış ve üretmişlerdir. Elde edilen sonuçlar, uygulanan kaplamaların saydam olduğunu, iyi bir yapışma ve test edilen koşullar altında dikkate değer bir antibakteriyel aktivite sergilediğini göstermiştir [10].

Islak zemine sahip ortak kullanım alanları olan tuvaletler, lavabolar, klozet ve buralarda kullanılan diğer gereçler bakteri üremesi için çok uygun bir ortam oluşturmaktadır ve hastalıklara hatta bazen salgınlara yol açmaktadır. Bu çalışmasında üretilecek olan antibakteriyel sırların bu gibi ortamlarda kullanılarak, kullanıldığı yerlerde hastalık yapıcı mikroorganizmaların oluşmasına engel olması amaçlanmaktadır. Bu çalışmayı diğer çalışmalardan farklı yapan nokta bugüne kadar kalsiyum boratlı sırların antibakteriytel özelliklerinin incelenmemiş olmasıdır. Bu kapsamda, kalsiyum 


\section{Nevşehir Bilim ve Teknoloji Dergisi (2019), 9 (IMSTEC Özel Say1),31-38}

boratlı $\left(\mathrm{CaB}_{2} \mathrm{O}_{4}\right)$ antibakteriyel sırlar hazırlanmış ve antibakteriyel özellikleri incelenmiştir. Antibakteriyel etki için yüksek antibakteriyel aktiviteye sahip olan gümüş $(\mathrm{Ag})$ tercih edilmiş ve sır bileşeninin içerisine molce \%0,5 gümüş katılmıştır.

\section{Materyal ve Metot}

\subsection{Antibakteriyel Tozların Hazırlanması}

Katkısız ve \%0,5 Ag katkılı $\left(\mathrm{Ca}_{0,995} \mathrm{Ag}_{0,5} \mathrm{~B}_{2} \mathrm{O}_{4}\right)$ kalsiyum borat tozunun üretilmesinde sol-jel yöntemi kullanılmıştır. Çalışmada \%99,9 saflıkta kalsiyum nitrat, borik asit, üre ve gümüş nitrat kullanılmıştır. İlgili reaksiyon denklemi aşağıdaki gibidir.

$3 \mathrm{Ca}\left(\mathrm{NO}_{3}\right)_{2}+6 \mathrm{~B}(\mathrm{HO})_{3}+3 \mathrm{H}_{4} \mathrm{CN}_{2} \mathrm{O}+4 \mathrm{NH}_{3} \rightarrow 3 \mathrm{Ca}\left(\mathrm{BO}_{2}\right)_{2}+8 \mathrm{~N}_{2}+3 \mathrm{CO}_{2}+21 \mathrm{H}_{2} \mathrm{O}$

Gerekli kimyasal hesaplamalar yapıldıktan sonra stokiometrik oranda hazırlanan kalsiyum nitrat, borik asit ve üreden oluşan solüsyon manyetik balık yardımıyla 1 saat karıştırılmış ve etüvde $110^{\circ} \mathrm{C}$ 'de kurutulmuştur. XRD analizi için, etüvde kurutulup hazırlanan katkısız kalsiyum borat tozu $850^{\circ} \mathrm{C}$ 'de 2 saat pişirilmiş ardından oda sıcaklığına kadar soğutulmuştur. Elde edilen ürün havan yardımıyla öğütülmüştür. Tozların morfolojik ve kristal incelemeleri XRD yöntemi ile Bruker AXS D8 Advance cihazı ile incelenmiştir.

\subsection{Antibakteriyel Sırların Uygulanması ve Pişirilmesi}

Katkısız ve \%0,5 Ag katkılı kalsiyum borat tozundan 2g. alınarak 1,5 ml. su ilavesi ile havanda karıştırılmıştır. Daha sonra sır $2 \mathrm{~cm} \times 2 \mathrm{~cm}$ engopsuz seramik altlık üzerine firça ile uygulanarak $950^{\circ} \mathrm{C}$ 'de 1 saat pişirilmiştir

\subsection{Antibakteriyel Test}

Antibakteriyel test, sırlı seramik yüzeyin antimikrobiyal aktivitesinin kantitatif bir değerlendirmesini yapmaya hizmet eder. Antibakteriyel test için E. coli bakterisi seçilmiştir. Şekil 1'de seramik malzemelerde antimikrobiyal performans verilmiştir [11].

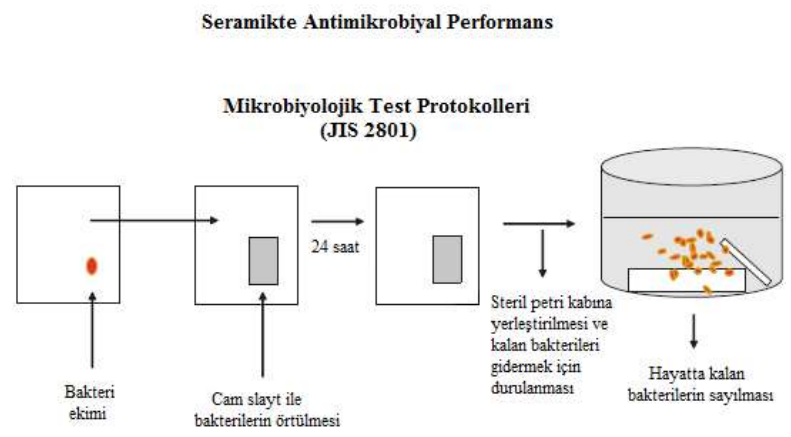

Şekil 1. Seramik malzemelerde antimikrobiyal performans

Ag katkılı ve katkısız kalsiyum borat sırlı seramik karoların antibakteriyel aktivitesi Japon Endüstriyel Standart (JIS) Z2801:200021'e göre yapılmıştır [12]. 


\section{Bulgular}

Katkısız ve \%0,5 Ag katkılı kalsiyum borat tozlarının XRD analizleri Bruker AXS D8 Advance cihazında yapılmıştır. Şekil 2'de katkısız kalsiyum borat tozunun XRD spektrumu verilmiştir. Şekil 3'de \%0,5 Ag. katkılı kalsiyum borat tozunun XRD spektrumu verilmiştir. Şekil 3'de piklerde farklılığa neden olan oluşan AgO'in pikleridir.

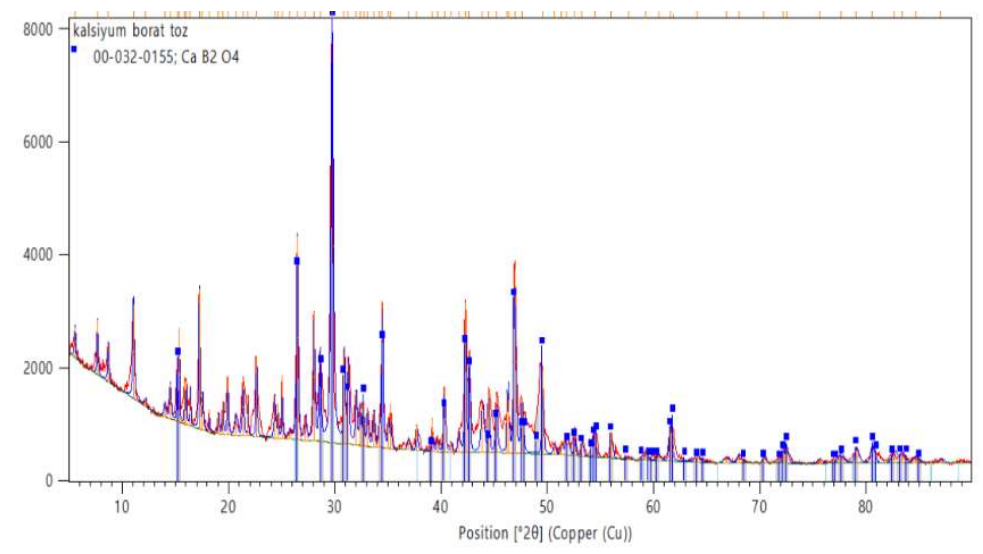

Şekil 2. Katkısız Kalsiyum Borat Tozunun XRD Spektrumu



Şekil 3. \%0,5 Ag Katkılı Kalsiyum Borat Tozunun XRD Spektrumu 
Nevşehir Bilim ve Teknoloji Dergisi (2019), 9 (IMSTEC Özel Sayı),31-38

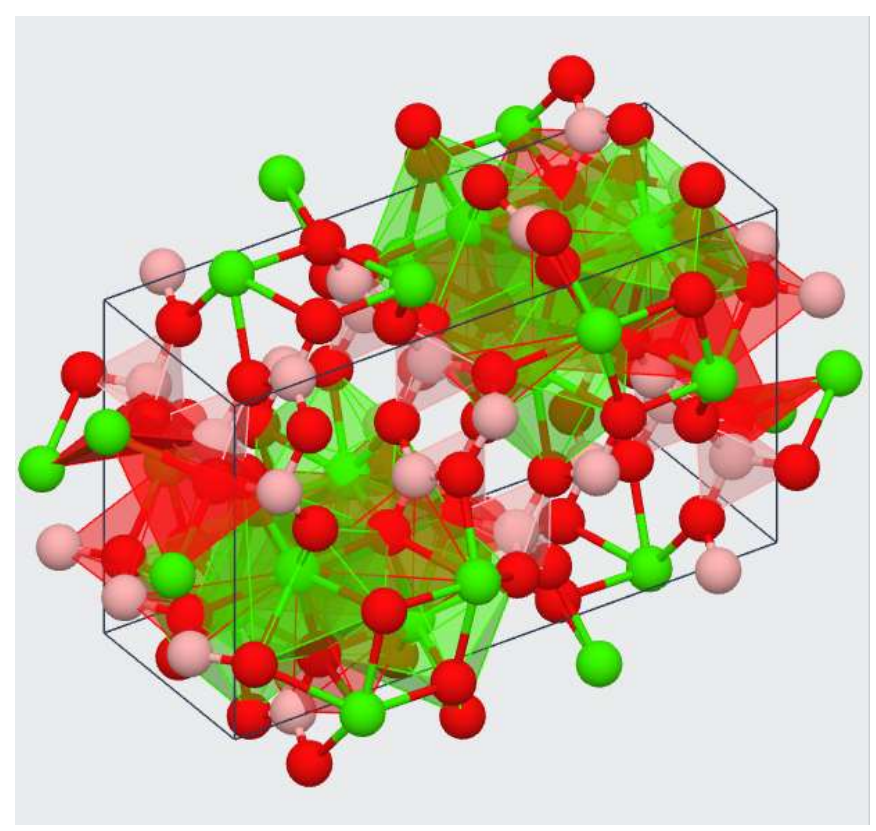

Şekil 4. Kalsiyum Boratın $\left(\mathrm{CaB}_{2} \mathrm{O}_{4}\right)$ Kristal Yapısı

Şekil 4'de kalsiyum boratın $\left(\mathrm{CaB}_{2} \mathrm{O}_{4}\right)$ kristal yapısı verilmiş̧tir. Sol-jel yöntemi ile antibakteriyel tozlar hazırlandıktan sonra bu tozlardan $2 \mathrm{~g}$. alınarak $1,5 \mathrm{ml}$. su ilavesi ile havanda karıştııılmıştır. Daha sonra sır $2 \mathrm{~cm} \times 2 \mathrm{~cm}$ engopsuz seramik altlık üzerine firça ile uygulanarak $950^{\circ} \mathrm{C}$ 'de 1 saat pişirilmiştir. Üretilen katkısız ve \%0,5 Ag. katkılı kalsiyum boratlı sırların seramik altlık üzerine uygulanıp pişirilmiş görüntüleri Şekil 5 ve Şekil 6’da verilmişsir.



Şekil 5. Üretilen Katkısız Kalsiyum Boratlı Sırın Seramik Altlık Üzerine Uygulanıp Pişirilmiş Görüntüsü 


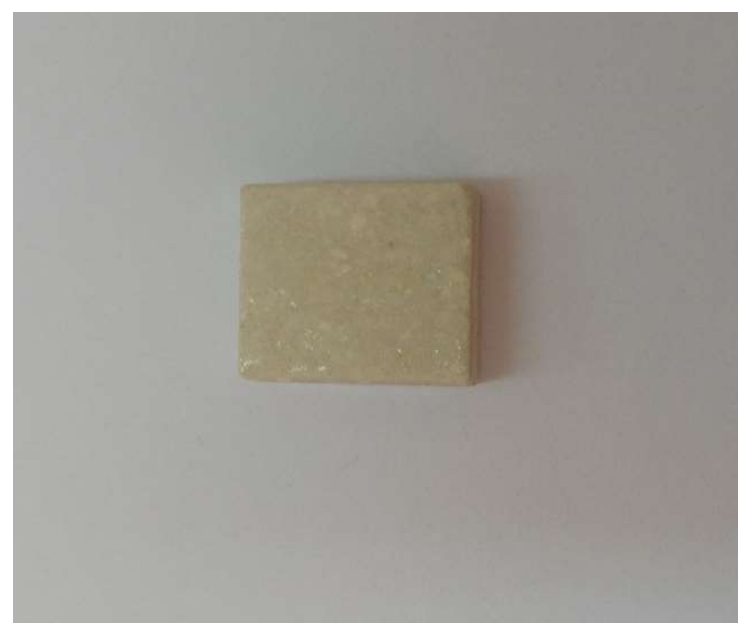

Şekil 6.Üretilen \%0,5 Katkııı Kalsiyum Boratlı Sırın Seramik Altık Üzerine Uygulanıp Pişirilmiş Görüntüsü

Daha sonra katkısız ve \%0,5 Ag katkılı kalsiyum borat sırlı seramik karolar antibakteriyel teste tabi tutulmuştur. Şekil 7’de katkısız ve \%0,5 Ag. katkılı kalsiyum boratlı sırların antibakteriyel test sonuçları verilmiştir.



Şekil 7. Katkısız (a) ve \%0,5 Ag katkı1ı (b) kalsiyum boratlı sırların antibakteriyel test sonuçları

Katkısız numunede koloni sayısı sayılamayacak kadar çoktur. \%0,5 Ag katkılı numunede koloni sayısı azalmıştır. \%0,5 Ag katkılı kalsiyum borat sırlı seramik karoların E.coli üzerinde antibakteriyel etkiye sahip olduğu tespit edilmiştir.

\section{Tartışma ve Sonuç}

Baheiraei, N. Ve diğerleri sol-jel yöntemiyle sırlı seramik karolarda $\mathrm{Ag} / \mathrm{SiO}_{2}$ ince filmin hazırlanması ve antibakteriyel aktivitesini incelemiş̧lerdir. Kaplama filmleri, Gram-pozitif Staphylococcus aureus ve Gram-negatif Escherichia coli bakterilerine karşı mükemmel bir antibakteriyel performans sergilemiştir [5].

Seabra, M. P., ve diğerleri, antimikrobiyal etkili porselen karolar üretmişlerdir. Bu çalışma, antimikrobiyal (uzun bir sure boyunca bakteri üremesine karşı etkili davranma) ve anti-leke (kolay temizleme) eylemleri ve yüksek kimyasal dayanıma sahip olan preslenmiş porselen karoların gelişimini sunmaktadır. Antimikrobiyal etki, Gram-pozitif Staphylococcus aureus ve Gram-negatif Escherichia coli bakterilerinin indirgenmesi ile kanıtlanmıştır. Üretilen porselen karolar, S. aureus ve E. coli bakterileri için sırasıyla \% 77 ve \% 81'in üzerinde bir popülasyon azalmasını.göstermiştir. Optimize edilmiş ürün, endüstriyel olarak hazırlanan macuna ağırlıkça\% 2.5 siyah bir seramik pigmenti ilave edildikten sonra az miktarda sır uygulanarak elde edilmiştir. Son olarak aktif yüzeyi elde etmek için kimyasal (ağırlıkça\% $98 \mathrm{NaNO}_{3}$ ve ağırlıkça\% 2 $\mathrm{AgNO}_{3}$ çözeltisi) ve termal $\left(430^{\circ} \mathrm{C}\right.$ de 2 saat) işlemler uygulanmıştır [2]. 


\section{Nevşehir Bilim ve Teknoloji Dergisi (2019), 9 (IMSTEC Özel Sayı),31-38}

Wang, Q., ve diğerleri mikro incelikte $\mathrm{Ag}_{2} \mathrm{WO}_{4}$ antibakteriyel tozların hazırlanması ve sıhhi seramiklerde uygulanması üzerine çalışma yapmışlardır. Mikro incelikte $\mathrm{Ag}_{2} \mathrm{WO}_{4}$ tozu \%90 oranında antimikrobiyal etkiye sahiptir ve iyi bakterisit etki sergilemektedir. $\mathrm{Ag}_{2} \mathrm{WO}_{4}$ antibakteriyel tozu içeren antibakteriyel sırlı seramikler 3 ay boyunca asit ve alkaliye batırılmış ve antibakteriyel aktivitelerde çok az değişiklik olmuş ve iyi antimikrobiyal dayanıklılık sağlanmıştır [7].

Yoshida, H., ve diğerleri gümüş kil antimikrobiyal ajanlı porselen sırın antimikrobiyal etkisini incelemişlerdir. Porselen sırların antimikrobiyal aktiviteleri ile gümüş kil minerallerinden yapılan antimikrobiyal ajanların antimikrobiyal aktiviteleri ve antimikrobiyal ajanlara katkıları araştırılmıştır. İndirgeyici bir atmosferde, 1573 K'de pişirilen kütlece \%10 antimikrobiyal ajana sahip olan sırlar negative antimikrobiyal aktiviteler göstermiştir. Diğer taraftan, kütlece \%1-10 antimikrobiyal ajana sahip sırların oksitleyici atmosferde antimikrobiyal aktiviteleri pozitif olmuştur. Kütlece \%0.008 Ag içeren sıra kütlece \%0,2 Zr eklenmesiyle yüksek bir antimikrobiyal aktiviteye sahip olmuştur. Bileşen analizi için kullanılan dalga boyu-dispersif X-1şını flüoresanı, negative aktivitenin, indirgeyici atmosferde pişirilen sırdaki Ag'in kaybolmasından kaynaklandığını göstermiştir [8].

Hasmaliza M., ve diğerleri seramik karo sırının içerisine mikron ve nano boyutta anataz katmışlar ve antibakteriyel performansını incelemişlerdir. Antibakteriyel özelliklerin kompozisyondaki anataz miktarı arttıkça arttığını gözlemlemişlerdir [9].

Niederhausern S. de., ve diğerleri endüstriyel seramik karoları yüzeylerinin temizlenebilirliğini ve antibakteriyel aktivitesini iyileştirmek için nano yapılı titanya-gümüş kaplama tasarlamış ve üretmişlerdir. Elde edilen sonuçlar, uygulanan kaplamaların saydam olduğunu, iyi bir yapışma ve test edilen koşullar altında dikkate değer bir antibakteriyel aktivite sergilediğini göstermiştir [10].

Literatürde bu konuyla ilgili yapılan çalışmalar incelendiğinde bugüne kadar boratlı sırların antibakteriyel özelliklerinin hiç çalışılmadığı tespit edilmiştir.

Yaptığımız çalışma sonucunda, \%0,5 Ag katkılı kalsiyum borat sırlı seramik karoların E.coli üzerinde antibakteriyel etkiye sahip olduğu tespit edilmiştir.

\section{Teşekkür}

Bu çalışma Erciyes Üniversitesi BAP Koordinasyon Birimi FDK-2019-9536” Boratlı Antibakteriyel Sırların Hazırlanması ve Karakterizasyonu “adlı projesiyle desteklenmektedir. Erciyes Üniversitesi BAP Koordinasyon Birimi’ne katkılarından dolayı teşekkür ederiz.

\section{Kaynakça}

[1] Noguera J. F., Moreno A., Gozalbo A., Orts M. J., 'DDevelopment of Ceramic Glaze Compositions with Bactericidal and Fungicidal Properties', Qualicer'10, 1-9, Spain, 2010.

[2] Seabra M. P., Grave L., Oliveira C., Alves A., Correia A., Labrincha J. A., 'Porcelain Stoneware Tiles with Antimicrobial Action', Ceramics International, 40, 6063-6070, 2014.

[3] Özcan S., Açıkbaş G., Açıkbaş N. Ç., "'Formation of Antibacterial Effect on Ceramic Tile Surfaces", Anadolu Üniversitesi Bilim ve Teknoloji Dergisi, Vol:18 Number:1,122-130, 2017.

[4] Oses J., Fuentes G. G., Palacio J. F., Esparza J., Garcia J. A. and Rodriguez R., Coatings, 197, 1-12, 2018. 
Nevşehir Bilim ve Teknoloji Dergisi (2019), 9 (IMSTEC Özel Say1),31-38

[5] Baheiraei N., Moztarzadeh F., Hedayati M., ' Preparation and Antibacterial Activity of Ag/ $\mathrm{SiO}_{2}$ Thin Film on Glazed Ceramic Tiles by Sol-Gel Method', Ceramics International, 38, 2921-2925, 2012.

[6] Mishra G., Dash B., Pandey S., Mohanty P. P., 'Antibacterial Actions of Silver Nanoparticles Incorporated Zn-Al Layered Double Hydroxide and Its Spinel', Journal of Environmental Chemical Engineering, 1, 1124-1130, 2013.

[7] Wang Q., Guo X., Wu W., Liu S., 'Preparation of Fine $\mathrm{Ag}_{2} \mathrm{WO}_{4}$ Antibacterial Powders and Its Application in The Sanitary Ceramics", Advanced Materials Research, Vols. 284-286, 1321-1325, 2011.

[8] Yoshida H., Abe H., Taguri T., Ohashi F., Fujino S., Kajiwara T., 'Antimicrobial Effect of Porcelain Glaze with Silver-Clay Antimicrobial Agent”, Journal of the Ceramic Society of Japan, 118[7], 571-574, 2010.

[9] Hasmaliza M., Foo H. S. and Mohd K., 'Anatase as Antibacterial Material in Ceramic Tiles”, Procedia Chemistry, 19, 828-834, 2016.

[10] Niederhausen S. de and Bondi M., 'Self-Cleaning and Antibacterial Ceramic Tile Surface', International Journal of Applied Ceramic Technology, 10 [6], 949-956, 2013.

[11] Fortuna D., Martini E., 'Antibacterial and self-cleaning glazes", Ceramic World Review n. 89/2010, 44-50.

[12] Anıl A., R Darshana B., Misra S. N., 'Studies on Various Functional Properties of Titania Thin Film Developed on Glazed Ceramic Wall Tiles”, International Journal of Modern Physics, Vol.22, 79-92, 2013. 